\title{
Direct photopatterning and SEM imaging of molecular monolayers on diamond surfaces: mechanistic insights into UV-initiated molecular grafting
}

Xiaoyu Wang ${ }^{\dagger}$, Paula Colavita ${ }^{\dagger}$, Kevin M. Metz $z^{\dagger}$, James E. Butler, Jr. ${ }^{+}$, and Robert J.

\author{
Hamers $^{\dagger *}$ \\ ${ }^{\dagger}$ Dept. of Chemistry, University of Wisconsin-Madison, 1101 University Avenue, \\ Madison, WI 53706
}

*Gas Dynamics Division, Naval Research Laboratory, Washington, DC

*Corresponding Author email: rjhamers@wisc.edu 
High-resolution XPS spectra of two regions of a single H-terminated nanocrystalline diamond sample that was immersed in TFAAD, partially covered with a mask, and then illuminated with UV light.

The samples were characterized using XPS in an ultrahigh vacuum system equipped with a load-lock for sample introduction, a monochromatized Al $\mathrm{K}_{\alpha}$ source (1486.6 $\mathrm{eV}$ ), and a hemispherical analyzer with a multichannel detector. Analyzer resolutions of 0.1-0.2 eV were used for XPS measurements. XPS peaks were baseline corrected and fit using Voigt functions. For TFAAD, the atomic area ratios, denoted as $\mathrm{A}_{\mathrm{F}(1 \mathrm{~s})} / \mathrm{A}_{\mathrm{C}(1 \mathrm{~s})}$, were calculated using the fit peak areas and correcting the ratio by the corresponding sensitivity factor $(\mathrm{C}, 0.296 ; \mathrm{F}, 1.00 ; \mathrm{N}, 0.477 ; \mathrm{O}, 0.711)$. The $\mathrm{A}_{\mathrm{F}(1 \mathrm{~s})} / \mathrm{A}_{\mathrm{C}(1 \mathrm{~s})}$ ratios were then used to quantify the extent of functionalization.

a) $\mathrm{C}(1 \mathrm{~s})$ and $\mathrm{O}(1 \mathrm{~s})$ (inset) of sample region that covered by the mask and therefore not exposed to UV light.

b) $\mathrm{C}(1 \mathrm{~s}), \mathrm{F}(1 \mathrm{~s}), \mathrm{N}(1 \mathrm{~s})$, and $\mathrm{O}(1 \mathrm{~s})$ spectra of sample region that was not covered by the mask and was therefore illuminated with UV light.

Comparing (a) and (b), note the characteristic changes in the $\mathrm{C}(1 \mathrm{~s})$ spectrum after TFAAD grafting due to the $\mathrm{CF}_{3}$ and $\mathrm{C}=\mathrm{O}$ groups of the TFAAD molecule. 


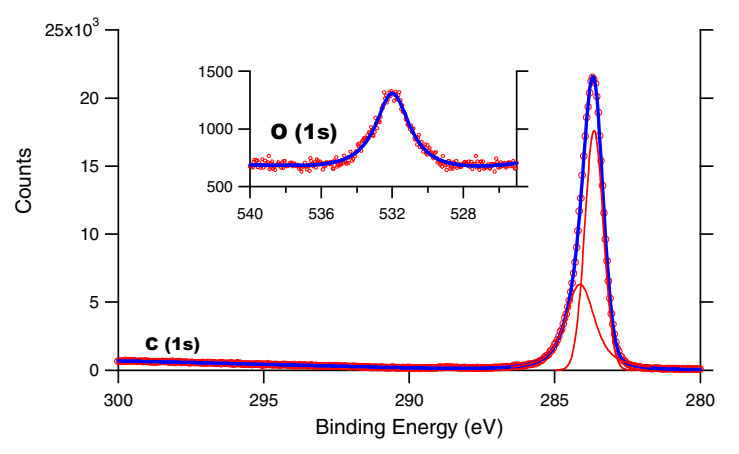

(b)
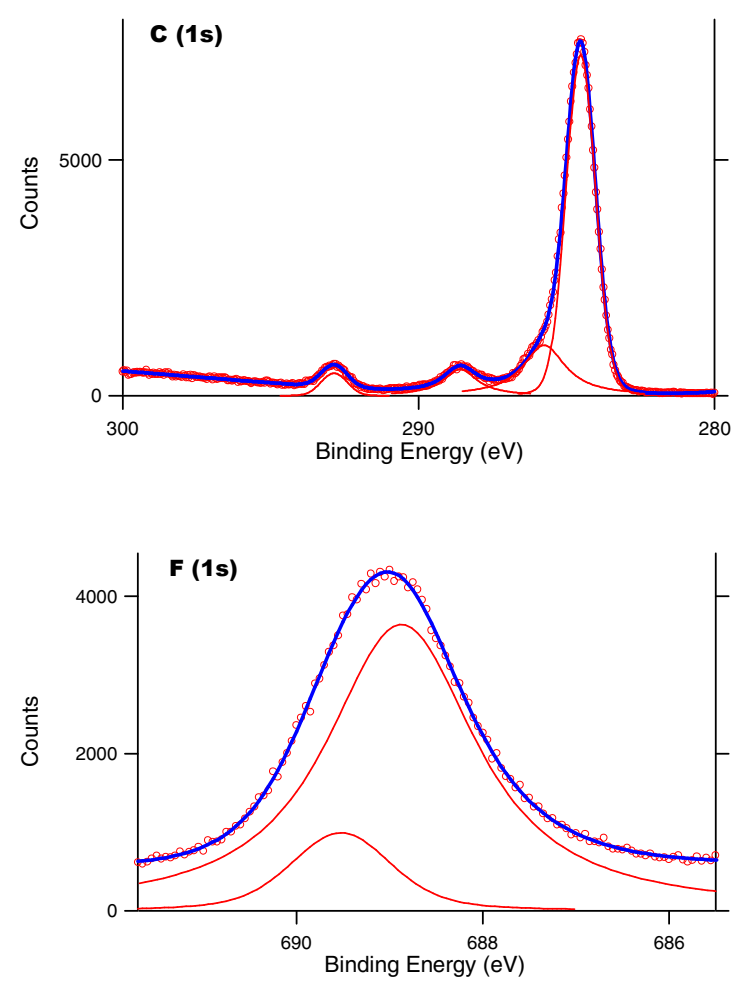

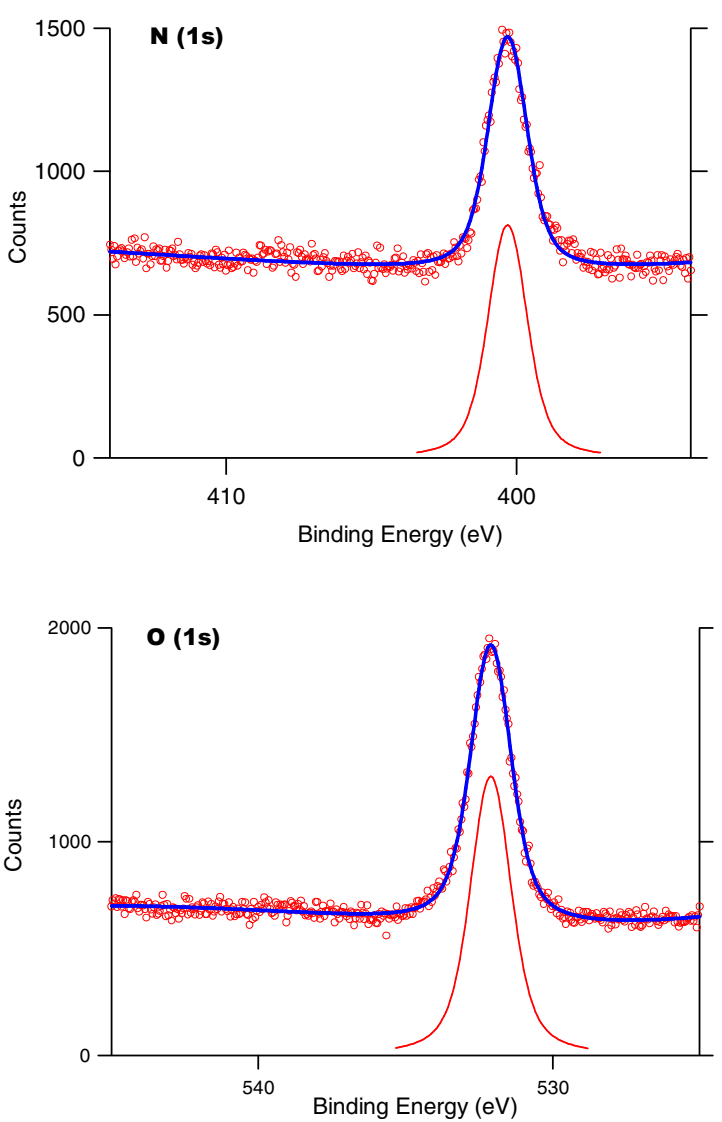